\section{BMJ Global Health}

\title{
Multisectoral action for health in low- income and middle-income settings: how can insights from social science theories inform intragovernmental coordination efforts?
}

\author{
Aloysius Ssennyonjo (D , , ${ }^{1,2}$ Sara Van Belle, ${ }^{2}$ Kristof Titeca, ${ }^{3}$ Bart Criel, ${ }^{2}$ \\ Freddie Ssengooba $^{1}$
}

To cite: Ssennyonjo A, Van Belle S, Titeca K, et al. Multisectoral action for health in low-income and middle-income settings: how can insights from social science theories inform intragovernmental coordination efforts?BMJ Global Health 2021;6:e004064. doi:10.1136/ bmjgh-2020-004064

Handling editor Seye Abimbola

Received 28 September 2020 Revised 17 April 2021 Accepted 19 April 2021

D Check for updates

(C) Author(s) (or their employer(s)) 2021. Re-use permitted under CC BY-NC. No commercial re-use. See rights and permissions. Published by BMJ.

${ }^{1}$ School of Public Health, Department of Health Policy Planning and Management, Makerere University College of Health Sciences, Kampala, Uganda

${ }^{2}$ Department of Public Health, Institute of Tropical Medicine, Antwerp, Belgium

${ }^{3}$ Institute of Development Policy, University of Antwerp, Antwerp, Belgium

Correspondence to Dr Aloysius Ssennyonjo; ssennyonjo@musph.ac.ug

\section{ABSTRACT}

There is consensus in global health on the need for multisectoral action (MSA) to address many contemporary development challenges, but there is limited action. Examples of issues that require coordinated MSA include the determinants of health conditions such as nutrition (malnutrition and obesity) and chronic non-communicable diseases. Nutrition, tobacco control and such public health issues are regulated separately by health, trade and treasury ministries. Those issues need to be coordinated around the same ends to avoid conflicting policies. Despite the need for MSA, why do we see little progress? We investigate the obstacles to and opportunities for MSA by providing a government perspective. This paper draws on four theoretical perspectives, namely (1) the political economy perspective, (2) principal-agent theory, (3) resource dependence theory and (4) transaction cost economics theory. The theoretical framework provides complementary propositions to understand, anticipate and prepare for the emergence and structuring of coordination arrangements between government organisations at the same or different hierarchical levels. The research on MSA for health in low/middle-income countries needs to be interested in a multitheory approach that considers several theoretical perspectives and the contextual factors underlying coordination practices.

\section{INTRODUCTION}

According to the World Health Organisation (WHO), health represents the collective effect of social, economic, and physical living conditions and health outcomes arising from an interplay of the societal conditions in which people are born, grow, live, work and age, referred to as social determinants of health. ${ }^{12}$ Health is increasingly recognised as an outcome of non-health sectors' actions such as the environment, economy, education, transport and food systems. $^{3} 4$ The Sustainable Development

\section{Summary box}

- Coordination of multisectoral action is critical to attaining health goals by leveraging the major assets for health improvement outside the health sector.

- Better application of (social science) theories would strengthen the study of complex phenomena like intragovernmental coordination.

- Insights from social science theories that consider interorganisational relations as a means for coordination contribute to understanding the reasons and conditions for developing such coordination arrangements; they highlight the obstacles and possible strategies for advancing coordinated government action for health.

- This multitheory approach's significant benefit rests on its wide and complementary theoretical basis, comprehensiveness, and descriptive and analytical potential.

- The research on the coordination of multisectoral action needs to encompass contextual factors and the interactions among these analytical domains.

- The theories can be applied to research that adopts an organisational perspective to coordination at and between the central and government levels.

Goals (SDGs) adopted in 2015 underscore the need to harness multisectoral action (MSA) defined as the health-enhancing actions from non-health sectors. ${ }^{5}$ Academic literature has focused on, for instance, (a) initiatives to address determinants of health conditions such as nutrition (malnutrition and obesity), ${ }^{6}$ nutritional status ${ }^{7}$ and chronic non-communicable diseases ${ }^{8}$; (b) establishment and implementation of public health programmes such as tobacco control, ${ }^{9}$ reproductive health ${ }^{10}$ or health promotion/ physical activity ${ }^{112}$; as well as (c) attainment 
of health outcomes such as the reduction in health inequities ${ }^{4}$ and early child development. ${ }^{13}$

Nutrition, tobacco control and such public health issues are regulated separately by health, trade and treasury ministries. Those issues need to be coordinated around the same ends to avoid conflicting policies. Despite the consensus that major assets for health and major determinants of ill-health are best addressed by the health sector coordinating with non-health sectors and actors, ${ }^{2}$ achieving such coordination is a chronic challenge. ${ }^{514}$ Following Elinor Ostrom, three inter-related problems undermine MSA regarding coordination, shared vision and politics. First, the coordination problem relates to bringing the actions of a diversity of actors into synergy. Second, it is not easy to build a common vision and consensus on a common objective among multiple actors engaged in a given context. Third, the political aspects pertain to the contestation and negotiation over interests, power, ideas and institutional contexts. ${ }^{15}$ Despite being a priority policy and operational question in many settings, how coordination among government agencies can be initiated, structured, maintained and sustained remains an understudied topic in public health literature. ${ }^{16-18}$

This paper takes a government perspective and focuses on intragovernmental coordination (ie, coordination among public sector organisations (ministries, departments and agencies (MDAs)) from various policy sectors). The central premise for this focus is that intragovernmental coordination is critical for attaining the objectives of MSA. ${ }^{18}$ Bouckaert et al, 19; p 9 emphasise that 'governments are inherently multi-organisational'. Hence, this paper considers coordination in government as an embodiment of interorganisational relations (IORs) among MDAs. Achieving coordination, defined as the "process by which a public sector organisation endeavours that their actions take into consideration the activities, resources and outcomes of other organisations', is a chronic challenge $\left(20 ; p\right.$ 9). ${ }^{21}$ In Uganda, for instance, conflicting, overlapping or duplicate mandates reportedly undermined the government's ability to address cross-cutting complex policy issues due to 'lack of synergies and coherence across sectors on what priorities are to be taken' (20; p 9) Similar experiences have been documented in other low/middle-income countries (LMICs). ${ }^{22-24}$

Several health policy and systems scholars argue for more and better use of theory for improving our ability to address health problems. They decry the inadequate rigour in research and suboptimal application of research to pragmatic ends. Van Belle $e t a l^{25}$ argue for applying social science theories in health policy and systems research to implement and evaluate better complex interventions. Recent reviews by Glandon $e t a l^{17}$ and Chircop et $a l^{26}$ reflect similar sentiments. For instance, Glandon $e t$ al advocated for 'stock-taking of the various ways in which multisectoral collaboration (MSC) is conceptualised, particularly given the substantial body of work on MSC theories in other fields like public administration' (17; $\mathrm{p}$ ii14). Such recommendation confirms the observation that current approaches to MSA would be enhanced by insights from public sector administration and organisational theory, where the thinking on this topic has advanced over time. ${ }^{52124}$

This paper presents four theoretical perspectives selected pragmatically based on organisational theory scholarship that considers IORs as a means for coordination. ${ }^{27}$ The selected theories are elaborated and complemented by empirical experiences from public administration and public health literature to discuss key considerations for research and practice concerning coordination within the governments in LMICs. The various decision-makers can also apply the theoretical perspectives within and outside the government to develop and facilitate coordinated efforts for crosscutting policy issues. Theoretical approaches could be descriptive, predictive and prescriptive. Therefore, a multitheory approach can be used at the initiation, implementation and evaluation of coordinated actions to diagnose (potential) problems and inform solutions. The theories could be used to examine coordination relationships and practices within and between policy domain(s), for example, health, environment, trade, and agriculture and policy issues that typically require MSA, for example, HIV/AIDS, nutrition and noncommunicable diseases $^{28}$

\section{INSIGHTS FROM THE THEORETICAL PERSPECTIVES}

This paper seeks to illustrate the potential contribution of four social science theories to studying the intragovernmental coordination phenomenon. The theoretical perspectives were as follows (1) transaction cost economics (TCE) theory, (2) principalagent theory (PAT), (3) resource dependence theory (RDT) and (4) the political economy (PE) perspective. The four theoretical approaches were selected because of the following rationale: first, they consider IORs as a means towards coordination. ${ }^{27}$ Second, they provide (at times, rival) explanatory logic on why and how organisations in one sector do or do not coordinate with others in other sectors to advance crosscutting objectives. Complex social phenomena such as coordination in multiorganisational settings can best be explained through a multifaceted multitheoretical approach. In a complementary manner, these theories would provide a holistic and comprehensive understanding of this complex phenomenon. ${ }^{29}$ The theoretical approaches that consider IORs as a means towards coordination have been grouped into two broad categories, namely (1) rational choice-based perspectives and (2) power-based theories. ${ }^{27}{ }^{30}$ Table 1 presents the main elements by which the theories are described and compared. These aspects are elaborated on in the next section. 


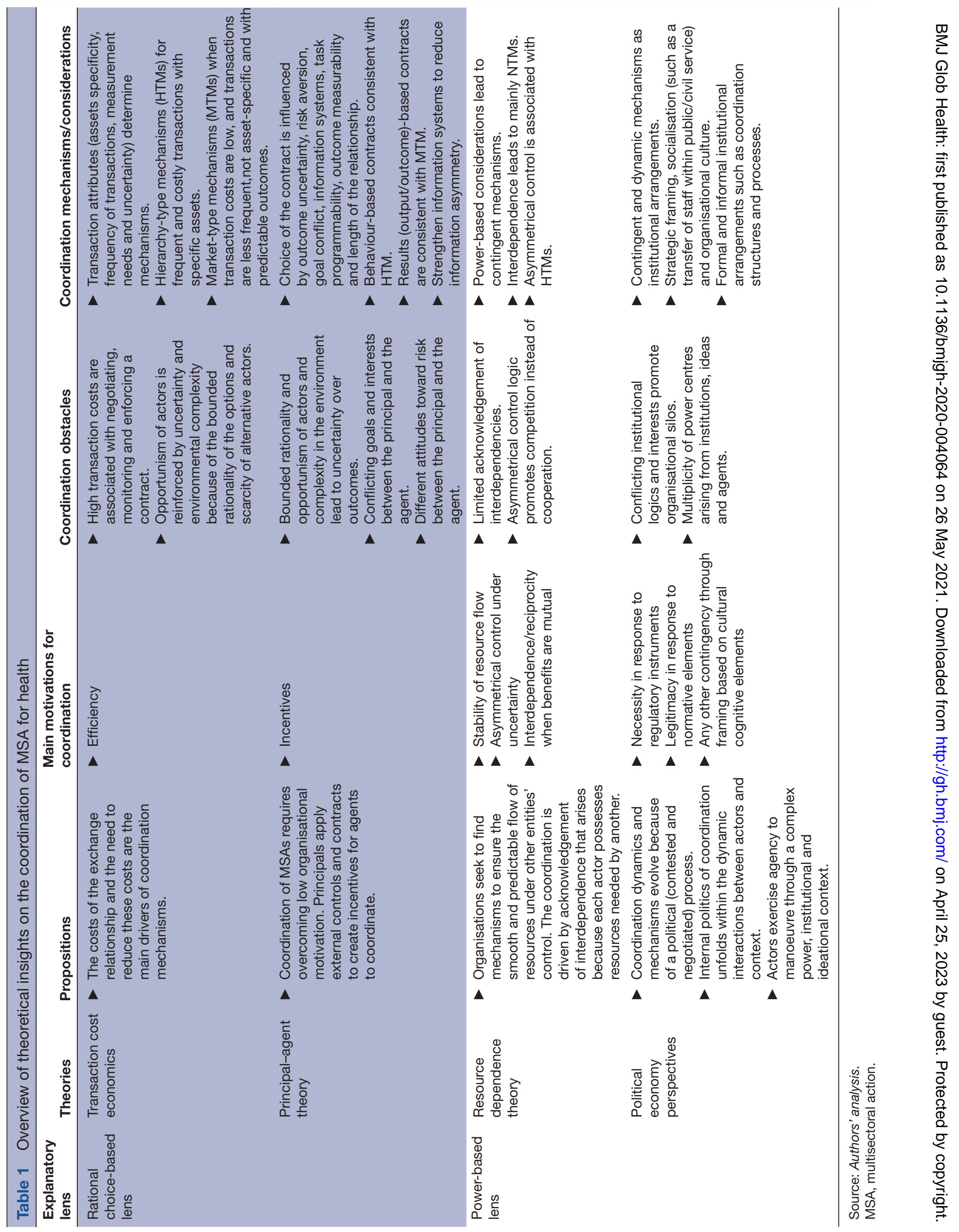




\section{Rational choice lens}

The TCE theory

The TCE posits that the actors choose their position to coordinate or not and organise interdependencies on considering costs of exchange relations. ${ }^{31-33}$ 'Transaction' is the main concept in TCE. The costs associated with these transactions become a central motivation of why and how to govern those exchange relations. TCE explains weak coordination between health and finance ministries by referring to high transaction costs (TCs). For example, physicians and economists use different language, care about different things and have trouble identifying shared values. ${ }^{34}$ These high TCs are a major obstacle to coordinated intragovernmental action. Coordination within government often gets down to exchanges between different MDAs. These exchanges exist within the following relations (1) politicians and bureaucratic officials, (2) one sector and another, or (3) government and non-state actors. Examples of exchanges in multisectoral arrangements include information, financial resources, staff and mandates. ${ }^{35}$ Understanding these exchanges becomes an entry to explore the obstacles and opportunities to enhance coordination among government entities. ${ }^{36}$

MSA for health is premised on the fact that some actions that contribute to health and well-being are better suited for organisations outside the health sector. ${ }^{34}$ This, in practice, might mean referral of duties from the health sector as a means of reducing workload for the sector. It also mandates the Ministry of Health (MOH) and government to develop mechanisms to coordinate the exchanges for MSA for health. TCE assumes public organisations to decide whether to coordinate (buy the goods or services from others) or not (to absorb the production function internally) based on perceived costs of exchanges. ${ }^{37}$ The TCE argues that organisations balance both internal production costs and TCs to keep these costs a minimum. ${ }^{30}$

Additionally, coordination will develop after internal considerations to improve efficiency and not desire to conform to mandate requirements or propensity to control or pursue mutually beneficial goals. ${ }^{38}$ Creating parallel or duplicate structures in the $\mathrm{MOH}$ to address cross-cutting issues is analogous to the 'make' decisions. Relinquishing some responsibility to other MDAs is analogous to a 'buy' decision. Therefore, the cost of the above actions by the health sector (MOH) is critical for decision-makers.

Organisations often perceive addressing cross-cutting objectives as resource-intensive ${ }^{39}$ and prioritise the mechanisms that minimise costs. The TCE predicts that the choice of coordination mechanisms in government dwells largely on the need to minimise the cost of coordinating transaction exchanges. ${ }^{27} 3140$ The TCE logic presents the market (outsourcing) and firm (internal production) as two extremes of coordination mechanisms. TCE also argues that the presence of bounded rationality reinforces the decision not to coordinate. The more specific the assets involved in the exchange relationship, the high uncertainty and bounded nature of the actors' rationality forces actors to prefer internal production of goods and services to minimise the cost of coordinating transaction exchanges. ${ }^{31}$ Thus, from the TCE perspective, hierarchical coordination arrangements within the entire government or a selected ministry are motivated by the need to reduce their business costs. ${ }^{40}$

Market exchanges could arise from referrals and outsourcing efforts. ${ }^{30}$ The frequency of exchange transactions and measurement challenges also matter in the choice of coordination mechanisms. When exchanges are frequent and measurement of results is difficult, organisations will prefer internal hierarchical-based coordination instruments. At the same time, infrequent transactions favour market-based coordination mechanisms. ${ }^{41}$ Hierarchical tools are a mainstay feature of coordination of MSA. Recent examples include the centralised incident command systems activated in countries like Uganda to coordinate the national COVID-19 responses. ${ }^{42}$

\section{Principal-agent or agency theory}

PAT looks at coordination arrangements as constitutive of principal-agency relationships. The principal-agency relations exist where a principal engages an agent to undertake certain tasks because the former have limited capabilities and are less efficient performing them. ${ }^{41}{ }^{43}$ PAT draws attention to the several principal-agent relations within an intragovernmental set-up. For instance, politician and civil servants are comparable with principals and agents, respectively. Politicians often articulate their broader goals and leave public officials to implement. Hence, this delegation causes uncertainty of results and the principal's (politicians) tendency to promote mandated multisectoral coordination to govern agents' (MDAs) actions. ${ }^{39}$ Other examples of principalagent relations in the context of MSA for health include those (1) between the health sector (specifically $\mathrm{MOH}$ ) and MDAs in other non-health sectors and (2) a relationship between a central level agency (like the Ministry of Finance) and the $\mathrm{MOH}$.

Agency theory posits that both the $\mathrm{MOH}$ or other MDAs (either as the principals or agents) are opportunistic and aim at maximising their interests. Examples of opportunistic behaviours include limited efforts by agents (moral hazard) or misrepresentation of abilities and hidden information (adverse selection). Empirical evidence suggests that agents usually have no incentive to coordinate and hence prioritise 'tasks which are of primordial importance to them, for which they are accountable and benefits them the most' (39; p 241). In addition to the coordination costs, the agents calculate the potential effects on their power and resources to decide whether to collaborate or not. ${ }^{39}$ The principal has to perform close monitoring of the agent because disparities in information lead to agents' tendency to engage in opportunistic behaviour. ${ }^{44}$ Information systems become a default tool for advancing coordinated actions. The 
principal can also achieve coordination by creating incentives to induce cooperative behaviours among the agents. The agency theory underscores contracts as coordination tools available to principals to align the agents' actions to their objectives. Two types of contracts are defined based on the ability to measure outcomes and the extent of the risk in getting results, namely (a) behaviour-based contracts or (b) outcome-based contracts. Behaviourbased contracts are preferred in instances of difficulty to measure outcomes, task programmability (ability to specify agent action in advance), uncertainty about the outcome, long-term relationships and risk-averse agents or principals. The principals monitor the agents' behaviours, such as participation in joint meetings and procedures as a proxy to the commitment to work in a coordinated manner.

Examples of behavioural-based contracts include coordination instruments for collective actions from health policy and systems research, including (a)collaborative planning through tools like health technology assessments ${ }^{45}$, (b) joint implementation arrangements such as one-stop shops, and (c) undertaking joint monitoring and reviews. ${ }^{46}$ Policy development stages such as agenda setting, policy formulation, implementation and evaluation can be useful entry points to explore the coordination process. ${ }^{47} \mathrm{~A}$ recent paper by Okeyo et a $t^{48}$ looking at coordination in the adoption phase of an intersectoral First 1000 Days Initiative targeting early childhood in South Africa is an example. Health policy and systems research (HPSR) literature on Health in All Policies (HiAP) approach covers a broad array of coordination issues during the adoption and implementation of policies. ${ }^{18} 2849$ Examples of policy or programme integration efforts include adopting national multisectoral nutrition policies, ${ }^{7}$ anti-tobacco legislation, ${ }^{50}$ and school health policies and programmes. ${ }^{51}$ Another common practice is monitoring the participation in the provision of social and health services around user groups such as children, elderly and women, such as multisectoral maternal and child health programmes. ${ }^{13}$

Outcome-based contracts are preferred where measuring outcomes is easy. They are also applicable when there is more certainty about outcomes, non-riskaverse agents, high goal conflict, limited task programmability and short-term relationship. ${ }^{27}$ Outcome-based contracts use performance-based contracts and incentives to reward outcomes. They are consistent with marketbased approaches such as result-based management tools advanced through new public management. ${ }^{52}$

The main limitation of the rational choice perspectives is their unidimensional conception of human behaviour. They assume an actor's actions to be static and predictable. These theories take for given the institutional context and the social and political process through which IORs occur. ${ }^{27}{ }^{30}$ From the above account, rationalbased theories must be complemented with theories that capture the dynamic interaction between agency (actors) and structure (context) and the values and power elements that characterise interorganisational relationships. The next section covers the RDT, followed by the PE perspective.

\section{Power-based lens}

The power-based theories conversely highlight the structural constraints in human agency. They underscore the fact that IORs are value-based and power-laden. ${ }^{27} 30$

\section{Resource dependence theory}

The RDT postulates that organisations seek to find coordination mechanisms to ensure a smooth and predictable flow of resources under other entities' control. Coordination is driven by the need to control external resources. The $\mathrm{MOH}$ and other MDAs consider mutually beneficial collaboration based on the interdependence that arises because each MDA possesses resources needed by another. ${ }^{53}$ The external environment includes, among other elements, the various government and nongovernment organisations that constitute the interorganisational context. To survive, organisations should continually seek to influence this environment to ensure stability and predictability of the flow of the resources outside their control. Coordination efforts 'serve as coping strategies to forestall, forecast, or absorb uncertainty to achieve an orderly, reliable pattern of resource flows and exchanges' (38; p 245). Consistent with this driver for coordination are coordination mechanisms such as stakeholder dialogues that serve as platforms to support information and resource-sharing and joint action. ${ }^{54}$

The RDT underscores the prominence of interdependence among different sectors. Mutual reliance on achieving common and specific development goals becomes a launchpad for effective coordination of MSA. For instance, objectives of non-health sectors such as education, agriculture and economy are dependent on having healthy and productive populations. ${ }^{24}$ From the RDT perspective, the expected coordination mechanisms are network-based, voluntary and based on negotiation, not coercion or imposition. However, higher authority can shape networks by determining their composition and processes. Thus, coordination in networks might be imposed, induced or mandated by a higher authority. ${ }^{19}$ The interdependence that arises when each actor possesses resources needed by others lead to IORs by the contingence of reciprocity. Resources involved in MSA for health as per RDT are broadly considered. They include finances, human resources, information, social support, authority, technology, access to political offices and acknowledgement. ${ }^{30}$ Reciprocity underlies the pursuit of interests and goals that are mutually beneficial. Coordination between the MOH and other MDAs is emphasised instead of control, power or domination in asymmetrical motivations. IORs based on the reciprocity contingency assume that resource scarcity leads to cooperation instead of competition. The process is 
characterised by harmony and mutual support rather than coercion and conflict.

Network theory and related concepts such as network governance, network management or networked government accentuate the nested nature of public sector organisations. ${ }^{556}$ Like RDT, network theory also acknowledges the dynamic interactions between (potential) collaborators and their environments. Consistent with Berg, ${ }^{57}$ power-based theories hold that coordinated action occurs in two sets of environments, namely 'internal' and 'external' organisational contexts. The two settings correspond to the two categories of coordination challenges faced in practice-vertical and horizontal difficulties. Vertical challenges arise because each coordinating entity is embedded in a web of other organisations. Through stakeholder analysis, ${ }^{58}$ the type and network of actors needed to address a problem or actualise the solutions can be identified and presented in a matrix linking issues and actors. ${ }^{36}$ Researchers can use tools such as social network analysis ${ }^{596}$ to describe the intensity and scope of the IORs. The WHO EURO governance mapping tool is another example of such instruments. ${ }^{61}$

In the context of government, each MDA or part thereof is part of larger systems and networks. Horizontal challenges arise because there are variations among organisations at the same hierarchical level regarding goals, strategies, language and work routines. For example, how results are registered and reported may vary across organisations. ${ }^{57}$ These internal and external linkages shape the action and decision spaces within which the actors can operate.

Asymmetrical motives in forming interorganisational interactions as evidenced by the desire to exercise power or reluctance to give up control over other organisations' resources have been documented (38; p 245). Power and control explain the inclination towards hierarchical coordination arrangements. The public sector coordination should be seen to operate within a political (contested and negotiated) environment characterised by manipulation, conflict, information distortion, coercion and exploitation. ${ }^{62}$ Empirical evidence further shows it is difficult to achieve coordination in networked relationships. Documented issues related to which sector should lead or where the secretariat for MSA should be housed. ${ }^{63}$ Therefore, considerable time and energy are required to establish and maintain overtime mechanisms to facilitate coordinated actions to address interdependent development problems. ${ }^{52464}$

\section{The PE perspective}

Although some of its elements have been discussed under the preceding theories, the PE viewpoint is increasingly considered a separate analytical lens in many health policy and systems studies ${ }^{24}$ and is worth examining in depth. The PE perspective considers coordination a political phenomenon marked by conflict, contestation and negotiation over ideas, interests and power. IORs evolve because of political (ie, negotiated and often contested) processes. Various organisations are competing to shape policies, institutions and resources for coordination. ${ }^{52465}$ The PE lens provides a foundation to study how power embedded in institutions and ideas is exercised by actors to shape the how and why of multisectoral coordination. ${ }^{63}$

The institutional-structural context embodies power and determines what agents (individual or collective actors) can and cannot do and consider as achievable by providing resources and constraints. Actors exercise agency to manoeuvre through a complex institutional and ideational context determined by power dynamics. This leads to conflicting interests and policy actions. One illustrative example of incoherence in priorities across government ministries concerns health workforce planning in Uganda. ${ }^{66}$ Whereas the $\mathrm{MOH}$ advocates for the recruitment of additional health workers, the Ministries of Finance and Public Service prioritise cost containment through establishing a wage bill ceiling. Conversely, the Ministry of Foreign Affairs advances policies for labour export.

Consistent with power-based theories, asymmetrical motives in the formation of IORs are characterised by the desire to exercise power or reluctance to give up control over other organisations' resources. ${ }^{27}$ Government MDAs tend to resist external control by another agency and resort to turf wars over mandates to maintain independence, thereby undermining coordination efforts. ${ }^{5}$ For instance, Mauti et al documented that the HiAP strategy in Kenya was hampered by concerns by non-health sectors that such initiatives perpetuate asymmetrical intentions of 'health imperialism'. ${ }^{67}$

PE supports generating politically feasible solutions and ensures realistic expectations of what can be achieved. ${ }^{62}$ Coordination must be proactively sought, and collective efforts require political work to be sustained. The PE perspective illuminates the political actions that MDAs engage in to facilitate or constrain coordination among government entities. Examples of political actions include dialogue, coalition building, backdoor deals, bureaucratic politics, lobbying, campaigning, turf wars and framing. ${ }^{65}$ By implication, a coordinated approach can be strengthened using different forms of power. Regulative institutional elements explain necessity as the main contingency for formation coordination arrangements and mechanisms. ${ }^{68}$ In this case, coordination is mandated by higher authorities (higher government agency, regulatory body, professional body), and organisations respond positively to meet legal or regulatory imperatives. The actors consider the anticipated consequences of non-compliance (eg, resource loss) to conform to mandated relations.

Power entrenched in ideas (ideational power) is critical for coordination. Developing a common mental frame (vision) is vital for coordination to ensue. Some efforts on coordination have focused on the strategic framing of problems and solutions. ${ }^{69} 70$ Institutionalisation and entrenchment of such frames are associated with the development of broader government reforms in 
developed countries such as 'Joined up' government in the UK, 'Whole of Government' in Australia and Horizontal government in Canada. ${ }^{19}$

Normative elements of institutions motivate actor (in)action based on the notion of appropriateness. ${ }^{68}$ Premised on this logic, organisations will coordinate to improve their legitimacy by conforming to prevailing institutional environments (norms, beliefs, values and expectations) from external actors. Engagement in coordination can be considered an organisation's motive to 'demonstrate or improve its reputation, image, prestige, or congruence with prevailing norms in its institutional environment' (38; p 246). Societal values such as trust have more explanatory power than other reasons for coordination decisions. For instance, trust can be a particularly important mediator of TCs. Where trust exists, the need for monitoring performance and information is lessened. ${ }^{30}$ These institutional elements derive conformity and lead to more voluntary coordination arrangements.

In summary, this section covered four theories useful to understand and explain obstacles and opportunities to intragovernmental coordination and MSA for health. The four theoretical lenses implicitly or explicitly recognise that government organisations exist within an environment constituent of other organisations, although emphasising different elements. Several factors, external and internal to government, interact in complex ways to shape coordination within the government in LMICs. ${ }^{18}$ These aspects are worth attending to and are discussed in the next section.

\section{CONTEXT AND INTRAGOVERNMENTAL COORDINATION}

The theories above indicate that MDAs are not necessarily independent and autonomous entities. Every organisation has an internal and external dimension that influences how and why it coordinates with other entities. ${ }^{71}$ Considering government as a whole, there are also intragovernmental factors and external contextual elements vital for intragovernmental coordination. In global health, these realities have been highlighted in studies looking at global influences on national health policies, ${ }^{72}$ policy transfer ${ }^{73}$ and health governance. ${ }^{74}$ The following section blends public sector management scholarship and public health literature to elaborate the coordination context for the government as a whole or for individual MDAs. Our analysis follows other researchers to distinguish the external government and internal government context as analytical constructs. However, in reality, these dimensions are intertwined. ${ }^{18}$

\section{External government context}

Exogenous factors positively associated with increased demand for coordination include regional and international cooperation and related development agendas. As countries engage in international exchanges such as trade negotiations, they must build internal policy coherence at the national level. ${ }^{75}$ Global development agendas such as the SDGs and Universal Health Coverage have recently renewed interest in MSA for health. ${ }^{1476}$ Similarly, international policies and related instruments such as the Framework Convention for Tobacco Control have provided means to drive coordination at the national level. ${ }^{5077}$

At times, the donors or non-state actors in LMICs act as principals mandating or facilitating multisectoral initiatives and bearing mixed effects on intragovernmental coordination. ${ }^{78} 79$ Experiences from the Global Fund against Malaria, TB and HIV/AIDS requiring a functional country coordination mechanism to oversee the utilisation of their finances are examples of donors inducing and facilitating coordination at the national level. ${ }^{80}$ The donor community also funded the establishment of National AIDS Commissions in several African countries as coordination structures for multisectoral HIV/AIDS response. ${ }^{81}$ The downside of this plethora of non-state actors and donors is the increased coordination and accountability problems within the internal government context. ${ }^{69}$

\section{Internal government context}

Conditions inherent to the government politicoadministrative system influence the need and design for coordination arrangements. The public sector in many countries is characterised by organisational specialisation and fragmentation. ${ }^{71}$ These institutional and structural attributes were amplified by reforms over the last three decades based on New Public Management (NPM) and democratic governance principles. ${ }^{3540}$ The NPM perspective, informed by TCE and agency perspectives, led to administrative reforms such as decentralisation and privatisation in several countries. ${ }^{82}$ One recent example is the devolution in Kenya, where the organisation and delivery of health services were assigned to the county level. ${ }^{83}$ 'Agencification'-creating autonomous public agencies such as authorities and councils-is typical of these reforms. ${ }^{84}$ One example is establishing independent national health insurance agencies, such as the National Health Insurance Authority in Ghana in $2004 .^{85}$

Reforms influenced by the World Bank's good governance principles and the Bamako Initiative (characterised by the introduction of user fees in health facilities) emphasised the need for participatory decision-making, arguing that lower government levels be empowered to make decisions about their affairs. ${ }^{82}$ The introduction of participatory decision-making structures (eg, village health councils) and decentralisation in LMICs are the major outcomes of these reforms. ${ }^{40}$ Overall, both NPM and democratic reforms led to a multiplication of actors, fragmentation of decision-making (with a detrimental impact on coordination towards health goals) ${ }^{86}$ and a decreased control by the central government apparatus over policymaking and implementation. ${ }^{1940}$ In some cases, privatisation of public services (through outsourcing/ contracting or public-private partnerships) was undertaken. The above centripetal inter/ intraorganisational 
linkages and related legal and institutional architecture and the centrifugal counter-reforms form the backbone of most countries' current internal government context. Recentralisation, the main feature of recently instigated counter-reforms, has been on the agenda in developing countries such as Uganda, ${ }^{87}$ Kenya $^{88}$ and South Africa. ${ }^{89}$ For instance, in Uganda, the government created a delivery unit under the prime minister's office to coordinate the second National Development Plan implementation across all MDAs. ${ }^{90}$

\section{METHODOLOGICAL CONSIDERATIONS: TOWARDS A MULTI- THEORETICAL APPROACH TO INTRAGOVERNMENTAL COORDINATION}

This paper did not aim to explore all theories relevant to the study of coordination within the government. The four perspectives were selected pragmatically based on scholarship on IORs as a means for coordination ${ }^{27}$ to illustrate the potential contribution of social theories to the study of the coordination phenomenon. ${ }^{17}$ Translation of these theories to research on interorganisational coordination could arise from their application within various LMIC settings with diverse political-administrative configurations. Since their main tenets are generic, the theoretical perspectives can have value in any environment, including high-income countries. The theories can be used to organise or map data. The constructs in the theories can be topics and themes for coding qualitative data. Researchers can apply these theoretical insights to cross-sectional and case study designs for in-depth inquiry into contextual conditions and drivers for coordination arrangements. ${ }^{17}$

The various decision-makers can also apply a multitheoretical approach within and outside the government to develop and facilitate coordinated efforts for crosscutting policy issues. Theoretical approaches could be descriptive, predictive and prescriptive. Therefore, a multi-theory approach can be used at the initiation, implementation, and evaluation of coordinated actions to diagnose (potential) problems and inform solutions. Such an approach could be used to guide research into coordination relationships within and between policy domain(s), for example, health, environment, trade, and agriculture and policy issues that typically require MSA, for example, HIV/AIDS, nutrition and non-communicable diseases. ${ }^{28}$

\section{CONCLUSION}

This paper elaborates the constructs and propositions from key theories on aspects of IORs within a government perspective. This paper intends to strengthen theory-based empirical evidence generation in HSPR on why and how government actors coordinate or not to achieve health and other development objectives. Researchers studying coordination within the same or between different government levels can draw on a multi-theory approach to explore, describe, and predict varying explanations of the how and why of coordination among different organisations.
According to TCE, the costs of exchange relationship are the main drivers of coordination and the choice of related mechanisms. Higher TCs explain the preference for internal production and hierarchical coordination mechanisms. Efficiency is the main contingency. Agency theory posits that intragovernmental coordination of MSA requires overcoming agents opportunism and self-interest and application of external control through contracts to create incentives to coordinate or not. Ease of performance measurement leads to a preference for outcome-based contracts (ie, market-type mechanism). In contrast, difficulty in measurement leads to behavioural-based contracts (ie, hierarchy-type mechanism).

The RDT postulates that organisations seek to find mechanisms to ensure the smooth and predictable flow of resources under the control of other entities. The coordination is driven by the contingency of stability. From the PE perspective, coordination dynamics and mechanisms evolve due to a political (contested and negotiated) process influenced by how the different actors conceive their motivations and balance multiple sets of interests and manoeuvre through a complex power, institutional and ideational context. This paper advances that combining the various theories when conducting HSPR would substantiate their explanatory and complementary value.

The insights from the selected theories help practitioners understand the logic that underlies their (potential) choices regarding coordination instruments. Each theory predicts obstacles and solutions to the performance of coordination efforts. The rational choice-based perspectives propose the behavioural assumptions of bounded rationality and opportunism of the actors as key constraints to multisectoral coordination. Information systems are vital in attenuating the information asymmetries and uncertainty in IORs. The power-based perspectives highlight the duality of interactions between actors and their environment as central to IORs. They underscore the fact that IORs within government are value-based and power-laden.

The theoretical perspectives emphasise the salience of the (a) nature and costs of exchange relationships (TCE), (b) incentives and contracts within principal-agent linkages (agency theory), interdependencies (RDT) and politics (PE) as key considerations in intragovernmental coordination efforts. The other important considerations include uncertainty and ease of measurement of outcomes, the role of institutions, ideas and interests. The insights derived from the theories and practice explain why it is extremely difficult for governments to work in a coordinated manner in any straightforward sense. There is a need to take these internal and external challenges and opportunities more seriously and not simply encourage MDAs to coordinate. The choice of the coordination mechanisms could be informed by the theoretical insights. The choice between hierarchy-type, market-type and hybrid-type mechanisms is contingent on the factors highlighted from the theories.

Public health scholarship and practice should be contextualised within broader social science theory to understand challenges and opportunities in achieving 
better-coordinated government action. The coordination of MSA also needs to pay attention to the aspects unique to government entities, especially the internal and external contextual factors. Consequently, this allows for contextualised diagnosis of coordination problems and determination of entry points to address them.

Twitter Aloysius Ssennyonjo @assennyonjo

Acknowledgements We acknowledge the SPEED for UHC Project at Makerere University School of Public Health (funded by the European Union) for providing the platforms for stakeholder deliberations that led to the conceptualisation of the $\mathrm{PhD}$ study from which this paper emanates. The related financial and technical support towards those endeavours is much appreciated.

Contributors AS wrote the initial draft as part of his $\mathrm{PhD}$ in Development Studies. SVB, KT, BC and FS provided intellectual content to the various drafts. All authors read and approved the final manuscript.

Funding This paper is a product of a PhD study supported by a DGD PhD grant at the Institute of Tropical Medicine, Antwerp, Belgium.

Competing interests None declared.

Patient consent for publication Not required.

Provenance and peer review Not commissioned; externally peer reviewed.

Data availability statement There are no data in this work.

Open access This is an open access article distributed in accordance with the Creative Commons Attribution Non Commercial (CC BY-NC 4.0) license, which permits others to distribute, remix, adapt, build upon this work non-commercially, and license their derivative works on different terms, provided the original work is properly cited, appropriate credit is given, any changes made indicated, and the use is non-commercial. See: http://creativecommons.org/licenses/by-nc/4.0/.

\section{ORCID iD}

Aloysius Ssennyonjo http://orcid.org/0000-0002-5790-4874

\section{REFERENCES}

$1 \mathrm{CSDH}$. Closing the gap in a generation health equity through action on the social determinants of health. final report of Commission on social determinants of health. Geneva: CSDH, 2008.

2 Kickbusch I, Gleicher D. Governance for health in the 21st century. Who 2012:1-106.

3 Kickbusch I, Behrendt T. Implementing a health 2020 vision: governance for health in the 21st century. World Heal Organ 2013;82.

4 Storm I, den Hertog $\mathrm{F}$, van Oers $\mathrm{H}$, et al. How to improve collaboration between the public health sector and other policy sectors to reduce health inequalities? - A study in sixteen municipalities in the Netherlands. Int J Equity Health 2016;15:97.

5 Rasanathan K, Bennett S, Atkins V, et al. Governing multisectoral action for health in low- and middle-income countries. PLoS Med 2017; 14:e1002285.

6 Callahan EA, Hollander M, McGhie DV, et al. Voices for healthy kids: a multisectoral collaboration to accelerate policy changes that promote healthy weight for all children and adolescents in the United States. BMJ 2018;363:k4763.

7 UNICEF. Multi-sectoral approaches to nutrition. New York: UNICEF, 2013: $1-4$.

8 Arora M, John S, Chauhan K, et al. Multi-Sectoral action for addressing social determinants of noncommunicable diseases and Mainstreaming health promotion in national health programmes in India. Indian J Community Med 2011;36:43.

9 Isett KR. In and across bureaucracy: structural and administrative issues for the tobacco endgame. Tob Control 2013;22 Suppl $1: i 58-60$.

10 Rasanathan K, Damji N, Atsbeha T, et al. Ensuring multisectoral action on the determinants of reproductive, maternal, newborn, child, and adolescent health in the post-2015 era. BMJ 2015;351:h4213.

11 Hämäläinen R-M, Aro AR, Lau CJ, et al. Cross-sector cooperation in health-enhancing physical activity policymaking: more potential than achievements? Health Res Policy Syst 2016;14:33.

12 Kang E. Intersectoral collaboration for physical activity in Korean healthy cities. Health Promot Int 2016;31:551-61.
13 Zaidi S, Bhutta Z, Hussain SS, et al. Multisector governance for nutrition and early childhood development: overlapping agendas and differing progress in Pakistan. BMJ Glob Health 2018;3:e000678.

14 Tangcharoensathien V, Srisookwatana O, Pinprateep P, et al. Multisectoral actions for health: challenges and opportunities in complex policy environments. Int $\mathrm{J}$ Health Policy Manag 2017;6:359-63

15 Ostrom E. Beyond markets and states: Polycentric governance of coMPlex econoMic systeMs. Am Econ Rev 2010;100:641-72.

16 Glandon D, Meghani A, Jessani N, et al. Identifying health policy and systems research priorities on multisectoral collaboration for health in low-income and middle-income countries. BMJ Glob Health 2018;3:e000970.

17 Glandon D, Mondal S, Okeyo I, et al. Methodological gaps and opportunities for studying multisectoral collaboration for health in low- and middle-income countries. Health Policy Plan 2019;34:I17-17.

18 Shankardass K, Muntaner C, Kokkinen L, et al. The implementation of health in all policies initiatives: a systems framework for government action. Health Res Policy Syst 2018;16:26.

19 Bouckaert G, Peters BG, Verhoest K. The coordination of public sector organizations, shifting patterns of public management. London: Palgrave Macmillan, 2010.

20 Government Of Uganda. Second national development plan Uganda. Natl Plan Auth Uganda 2015;1:344.

21 Emerson K. Collaborative governance of public health in lowand middle-income countries: lessons from research in public administration. BMJ Glob Health 2018;3:e000381.

22 Graham WJ, Kuruvilla S, Hinton R, et al. Multisectoral collaboration for health and sustainable development. BMJ 2018;363:k4868.

23 Milman HM, Castillo CA, Sansotta AT, et al. Scaling up an early childhood development programme through a national multisectoral approach to social protection: lessons from Chile Crece Contigo. BMJ 2018;363:k4513.

24 Bennett S, Glandon D, Rasanathan K. Governing multisectoral action for health in low-income and middle-income countries: unpacking the problem and rising to the challenge. BMJ Glob Health 2018;3:e000880.

25 Van Belle S, van de Pas R, Marchal B. Towards an agenda for implementation science in global health: there is nothing more practical than good (social science) theories. BMJ Glob Health 2017;2:e000181.

26 Chircop A, Bassett R, Taylor E. Evidence on how to practice intersectoral collaboration for health equity: a scoping review. Crit Public Health 2015;25:178-91.

27 Rossignoli C, Ricciardi F. Theories explaining inter-organizational relationships in terms of coordination and control needs. In: Rossignoli C, Ricciardi F, eds. nter-Organizational relationships towards a dynamic model for understanding business network performance. 2015th edn. Springer International Publishing, 2015: 7-36.

28 De Leeuw E, Peters D. Nine questions to guide development and implementation of health in all policies. Health Promot Int 2015;30:987-97.

29 Langley A. Strategies for theorizing from process data. Acad Manage Rev 1999;24:691-710.

30 Reitan TC. Theories of Interorganizational relations in the human services. Soc Serv Rev 1998;72:285-309.

31 Williamson O. Transaction-Cost economics: the governance of contractual relations. J Law Econ 1979;XXII, n. 2:233-61.

32 Williamson $\mathrm{O}$. The economics of organization: the transaction cost approach. Am J Sociol 1981;87:548-77.

33 Kaufman BE. The institutional economics of John R. commons: complement and substitute for neoclassical economic theory. Socioecon Rev 2007;5:3-45.

34 de Leeuw E. Engagement of sectors other than health in integrated health governance, policy, and action. Annu Rev Public Health 2017;38:329-49.

35 Peters BG. Managing horizontal government: the politics of coordination. Research Paper 1998.

36 Honadle G, Cooper L. Beyond coordination and control: an interorganizational approach to structural adjustment, service delivery, and natural resource management. World Dev 1989;17:1531-41.

37 Walker G, Weber D. A transaction cost approach to Make-or-Buy decisions. Adm Sci Q 1984;29:373.

38 Oliver C. Determinants of Interorganizational relationships: integration and future directions. Acad Manage Rev 1990;15:241-65.

39 Molenveld A, Verhoest $\mathrm{K}$. The fit between coordination arrangements and organizational characteristics 2018. 
40 Peters BG. The search for coordination and coherence in public policy: return to the center? unpublished paper. Department of Political Science. University of Pittsburgh 2005.

41 Rossignoli C, Ricciardi F. Inter-Organizational relationships. towards a dynamic model for understanding business network performance 2015.

42 WHO. COVID-19 strategy update. Geneva: WHO, 2020. https://www. who.int/publications/m/item/covid-19-strategy-update

$43 \mathrm{Kim}$ J, Mahoney JT. Property rights theory, transaction costs theory, and agency theory : an organizational economics approach to strategic management. Managerial and decision economics 2005;242:223-42.

44 Eisenhardt KM. Agency theory: an assessment and review. Acad Manage Rev 1989;14:57-74.

45 Kang E, Park HJ, Kim JE. Health impact assessment as a strategy for intersectoral collaboration. J Prev Med Public Health 2011;44:201-9.

46 Kriegner S, Ottersen T, Røttingen J-A, et al. Promoting Intersectoral collaboration through the evaluations of public health interventions: insights from key informants in 6 European countries. Int $\mathrm{J}$ Health Policy Manag 2020;2020:1-10.

47 Peters BG. The challenge of policy coordination. Policy Des Pract 2018:1:1-11.

48 Okeyo I, Lehmann $\mathrm{U}$, Schneider $\mathrm{H}$. The impact of differing frames on early stages of intersectoral collaboration: the case of the First 1000 Days Initiative in the Western Cape Province. Health Res Policy Syst 2020;18:3.

49 Tosun J, Lang A. Policy integration: mapping the different concepts. Policy Stud 2017;38:553-70.

50 Oladepo O, Oluwasanu M, Abiona O. Analysis of tobacco control policies in Nigeria: historical development and application of multisectoral action. BMC Public Health 2018;18:959.

51 Sidaner E, Balaban D, Burlandy L. The Brazilian school feeding programme: an example of an integrated programme in support of food and nutrition security. Public Health Nutr 2013;16:989-94.

52 Christensen T, Lægreid P. The Whole-of-Government approach to public sector reform. Public Adm Rev 2007;67:1059-66.

53 Pfeffer J, Salancik G. The external control of organizations: a resource dependence perspective. 1st ed. Stanford, California: Stanford Business Books, 2003.

54 Nabyonga-Orem J, Dovlo D, Kwamie A, et al. Policy dialogue to improve health outcomes in low income countries: what are the issues and way forward? BMC Health Serv Res 2016;16 Suppl 4:217.

55 Tenbensel T. Bridging complexity theory and hierarchies, markets, networks, communities: a 'population genetics' framework for understanding institutional change from within. Public Manag Review 2018;20:1032-51.

56 Klijn EH, Koppenjan JFM. Public management and policy networks: foundations of a network approach to governance. Public Manag An Int J Res Theory 2000;2:135-58.

57 Berg AM. What did happen to the public service professionals ? - Organisational reforms and professional roles. In: To the EGPA Annual Conference, Madrid, Spain, September 19212007 EGPA Study Group 3: Public Personnel Policies "Leadership, Professionalisation and HR Strategies" Sub Theme 2: Professionalisation. Madrid 2007:1-15.

58 Brugha R, Varvasovszky Z. Stakeholder analysis: a review. Health Policy Plan 2000;15:239-46.

59 Dornisch D. Network analysis of public sector coordination and collaboration : conceptual and methodological applications. Public Adm 1994;2005:37-46.

60 Ssengooba F, Kawooya V, Namakula J, et al. Application of social network analysis in the assessment of organization infrastructure for service delivery: a three district case study from post-conflict Northern Uganda. Health Policy Plan 2017;32:1193-202.

61 WHO Regional Office for Europe. Tool for mapping governance for health and well-being: the Organigraph method. Copenhagen: WHO Regional Office for Europe, 2018.

62 Mcloughlin C. Political economy analysis: topic guide. 2nd edn Birmingham, UK: GSDRC, University of Birmingham, 2014

63 Balarajan Y, Reich MR. Political economy challenges in nutrition. Global Health 2016;12:70.

64 Kuruvilla S, Hinton R, Boerma T, et al. Business not as usual: how multisectoral collaboration can promote transformative change for health and sustainable development. BMJ 2018;363:k4771.

65 Hudson D, Leftwich A. From political economy to political analysis. Dev Leadersh Progr 2014;123.

66 SPEED Project. Phasing out enrolled nurses in Uganda. Policy Issues Paper 2017.
67 Mauti J, Gautier L, De Neve JW. Kenya's health in all policies strategy: a policy analysis using Kingdon's multiple streams. Heal Res Policy Syst 2019;17:1-2.

68 Scott WR. Three pillars of institutions. Institutions Organ ideas Interes 2008:55-85.

69 Bump JB. Undernutrition, obesity and governance: a unified framework for upholding the right to food. BMJ Glob Health 2018;3:e000886.

70 Khayatzadeh-Mahani A, Ruckert A, Labonté R. Obesity prevention: co-framing for intersectoral 'buy-in'. Crit Public Health 2018;28:4-11.

71 Christensen T, Lægreid P. The challenge of coordination in central government organizations: the Norwegian case. Public Organ Rev 2008:8:97-116.

72 van de Pas R, Ssennyonjo A, Criel B. How are developments at global and regional levels influencing progress towards UHC in Uganda? implications for ensuring good health and well-being. In: Freddie S, Kiwanuka SN R, eds. Universal health coverage in Uganda: looking back and forward to speed up the progress. Kampala: Makerere University, 2017: 48-70.

73 Stone D. Learning lessons, policy transfer and the International diffusion of policy ideas. Working paper 69/01. 69. Centre for the Study of Globalisation and Regionalisation (CSGR), University of Warwick, 2001.

74 Cohn A. Intersectoral governance for health in all policies structures, actions and experiences. Rev. Direito Sanit. 2013;14:264.

75 Labonte R, Sanger M. Glossary on the world trade organisation and public health: Part 2. J Epidemiol Community Health 2006;60:738-44.

76 Nordbeck R, Steurer R. Multi-sectoral strategies as dead ends of policy integration: lessons to be learned from sustainable development. Environ Plann C Gov Policy 2016;34:737-55.

77 Sanni S, Hongoro C, Ndinda C, et al. Assessment of the multisectoral approach to tobacco control policies in South Africa and Togo. BMC Public Health 2018:18:962.

78 Ravishankar N, Gubbins P, Cooley RJ, et al. Financing of global health: tracking development assistance for health from 1990 to 2007. Lancet 2009;373:2113-24.

79 Orem Juliet N, Ssengooba F, Okuonzi S, et al. Can donor aid for health be effective in a poor country? assessment of prerequisites for aid effectiveness in Uganda. Pan Afr Med J 2009;1.

80 Garmaise D. Uganda CCM and the global fund at odds over funding Request. Aidspan, 2017. Available: http://www.aidspan. org/gfo_article/uganda-ccm-and-global-fund-odds-over-fundingrequest

81 Hongoro C, Akim JM, Kembo J. Review of national AIDS councils in Africa : Findings from five countries Review of national AIDS councils in Africa : Findings from five countries. SAHARA-J J Soc Asp HIVI AIDS 2012:54:192-200.

82 Bossert TJ. Decision Space and Capacities in the Decentralization of Health Services in FijiComment on "Decentralisation of Health Services in Fiji: A Decision Space Analysis". Int J Health Policy Manag 2016;5:443-4.

83 McCollum R, Theobald S, Otiso L, et al. Priority setting for health in the context of devolution in Kenya: implications for health equity and community-based primary care. Health Policy Plan 2018:33:729-42.

84 Verschuere B, Vancoppenolle D. Policy-Making in an era of agencification: an exploration of task divisions between politicians, core departments and public agencies. Policy and Society 2012;31:249-58

85 Dixon J, Tenkorang EY, Luginaah I. Ghana's National health insurance scheme: a national level investigation of members' perceptions of service provision. BMC Int Health Hum Rights 2013:13:35

86 Brinkerhoff DW, Brinkerhoff JM. Public sector management reform in developing countries: perspectives beyond NPM orthodoxy. Public Admin. Dev. 2015;35:222-37.

87 Cammack D, Golooba-Mutebi F, Kanyongolo F, et al. Neopatrimonial politics, decentralisation and local government Uganda and Malawi. London: Overseas Development Institute (ODI), 2007.

88 Barasa EW, Manyara AM, Molyneux S, et al. Recentralization within decentralization: County Hospital autonomy under devolution in Kenya. PLoS One 2017;12:e0182440.

89 Kroukamp H. Decentralisation or recentralisation: international lessons for South Africa. Acta Acad 2000;32:85-106.

90 Roberts N, Ssejjaaka S. Strengthening the coordination function at the office of the prime minister and sector working groups. final report. Office of the Prime Minister, Government of Uganda Kampala, 2017. https://www.ldpg.or.ug/wp-content/uploads/2017/ 05/SWG_OPM-Coordination-Assessment_3-May17.pdf 